\title{
Kronik bel-boyun ağrılı hastada opioid analjezikler
}

\section{Opioid analgesics in patients with chronic neck and low back pain}

\author{
Ruhiye Reisli \\ Necmettin Erbakan Üniversitesi, Meram Tıp Fakültesi, Anesteziyoloji ve Reanimasyon Anabilim Dalı, Algoloji Bilim Dalı, Konya
}

Kronik boyun ve bel ağrısı, birinci basamak hekimlerin en sık karşılaştıkları sağlık problemidir. Tedavi klavuzlarında asetominofen ve/veya Non sterid antiinflamatuar ilaçlar osteoartrit ve kronik bel ağrısı gibi ağrılarda birinci tercih tedavi seçeneği olarak kabul edilse de; Amerikan Geriatri Derneği ve Ulusal Sağlık Enstitüsü klavuzları mümkünse NSAi'lardan kaçınılmasını önermektedir. Kronik ağrı hastalarında ağrı tedavisi uzun süre devam edeceğinden, kronik analjezik kullanımının uzun dönem etkileri önem kazanmaktadır. Opioidler, prostaglandine baglı yan etkiler olmaksızın güçlü analjezik etkinlik sağlarlar. Non opioid analjeziklerin aşırı kullanımı, diğer tedavilere yetersiz cevap, ciddi fonksiyon kaybı ve rehabilitasyona katılımı engelleyen ciddi ağrı kronik boyun ve bel ağrısında opiod tedavisine başlama nedenleri olarak sıralanabilir. Opioid kötüye kullanım ve bağımlılık riski akılda tutulmalı ve bazı tedavi stratejileri oluşturulmalıdır.

Anahtar sözcülkler: kronik bel ağrısı; kronik boyun ağrısı; opioidler
Chronic back and neck pain are the two most common health problem in a primary care physician consultataion. Althought first line treatment for chronic back and neck pain begins with acetaminophen and nonsteroidal anti-inflamatory drugs(NSAID) in the treatment guidelines; American Geriatrics Society and The National Institute for Health and Care Excellence recomment against using NSAID if possible. Because treatment will last longer in chronic patients, the long-term effects of the analgesics become more important. Opioids offer stronger analgesic potency without prostaglandin related adverse events. Opioid therapy may also be considered when patients have failed to achive benefit from other pain therapies, are unable to tolerate non-opioid analgesics or have severe, disabling pain. The risk of misuse and abuse must be kept in mind and some treatment strategies planned.

Key words: chronic low back pain; chronic neck pain; opioids

\section{A} ğrı, birinci basamak sağlık merkezlerine başvuran hastaların en sık yakınma nedenidir ve bu hastaların yaklaşık \%10-20'si kronik ağrıdan şikayet eder. ${ }^{[1]}$ Kronik boyun ve bel ağrısı, birinci basamak hekimlerin en sık karşılaştıkları ağrı problemidir. Kanada ve İngiltere'de yapılan bir çalışmada, hastaların \%33'ünde son bir ay içerisinde en az bir hafta süren bel ve/veya boyun ağrısına rastlanmıştır. Son altı ay içerisinde ise bu oran \%80'dir. ${ }^{[2,3]}$ Kronik bel ağrısı, boyun ağrılarına göre daha sık görülür. Bel ağrısı yetişkin hastaların \%59'unda hayatlarının herhangi bir döneminde etkilendikleri en yaygın kronik ağrıdır. Londra'da yapılan çalışmada, genel popülasyonda kanser dışı kronik ağrı (KDKA) \%46,5 oranında saptanırken, en sık neden olarak bel ağrısı ve artritler belirtilmiştir. ${ }^{[1]}$
Kronik ağrı, sık görülen bir şikayet olmasına ve etkin ağrı tedavisinin yaşam kalitesini arttırdığı bilinmesine rağmen, birinci basamak sağlık merkezlerinde çalışan hekimlerin sadece \%15'i böyle bir hastayı tedavi ederken rahat olduklarını belirtmektedir. ${ }^{[4]}$ Portekizde, 1487 aktif kronik bel ağrılı hastada yapılan çalışmada, bu hastaların ancak \%18,7'sinin ağıı tedavisi için ilaç aldığı belirtilmektedir. Hastaların \%12,3'ü non-steroid anti-inflamatuvar ilaçlar (NSAii), \%1,6'sı opioid kullanmaktadır. Çalışmada, hastaların ciddi ağrılarında bile analjezik kullanımının çok az olduğu belirtilmiştir. ${ }^{[5]}$

Kronik bel ağrısında birinci seçeneğimiz asetominofen ve NSAii'dir. ${ }^{[6]}$ Shah ve arkadaşları NSAii ile tedavinin daha ekonomik olduğunu vurgulamaktadırlar. Opioidler, bel ağrılarında da en potent ve etkin

- İletişim adresi: Prof. Dr. Ruhiye Reisli, Necmettin Erbakan Üniversitesi, Meram Tıp Fakültesi, Anesteziyoloji ve Reanimasyon Anabilim Dalı, Algoloji Bilim Dalı, Konya Tel: 0532 - 7717337 e-posta: ruhiyereisli@gmail.com

- Geliștarihi: 20 Șubat 2017 Kabul tarihi: 20 Șubat 2017 
analjezikler iken, NSAii'den cevap almayan hastalarda kullanılmalıdır. ${ }^{[6]}$ Bu tezi savunan çalışmaların yanı sıra, kısa dönemde NSAii'nin etkin, ama uzun süreli kullanım ve aşağıda özetlenen bazı durumlarda kullanımlarının sakıncalı olduğunu savunan görüşler de bulunmaktadır. ${ }^{[7-12]}$

Asetaminofen, osteoartrit tedavisinde birinci seçenek olarak önerilir, fakat NSAii'den daha az etkilidir ve 4 gr'ı aşan dozlarda hepatotoksik etkisi mevcuttur. NSAii hafif ve orta dereceli ağrılarda etkindir, fakat bu ilaçların da doz bağımlı gastrointestinal, kardiyovasküler ve renal yan etkileri bulunmaktadır. Ciddi gastrointestinal yan etkilerin yanı sıra kronik NSAii kullanan hastaların \%24'ünde renal disfonksiyon, \%12'sinde renal papiller nekroz oluşmakta ve aşırı kullanımla risk artmaktadır. ${ }^{[7]}$ Aynı zamanda, NSAii'nin yaşlı hastalarda çok kullanılan antihipertansifler, warfarin, aspirin gibi ilaçlarla önemli etkileşimleri bulunmaktadır. NSAii, diüretiklerin etkinliğini azalttığından, kullanımıyla konjestif kalp yetmezliği riski artmaktadır. ${ }^{[8]}$ Osteoartrit ve kronik boyun/bel ağrısı ayrı ayrı önemli birer ağrı nedeni iken, sıklıkla beraber bulunur. Bu durumlara sıklıkla, obezite, kalp-damar hastalıkları ve kardiyovasküler risk faktörleri eşlik etmekte ve hastalardaki tedavi seçeneklerini etkilemektedir. ${ }^{[9]}$ Tedavi kılavuzlarında NSAii osteoartrit ve kronik bel ağrısı gibi ağrılarda birinci tercih tedavi seçeneği olarak kabul edilse de; Amerikan Geriatri Derneği (AGS) ve Ulusal Sağlık Enstitüsü kılavuzları (NICE), mümkünse NSAii'den kaçınılmasını önermektedir.

Asetaminofen veya NSAil'ye cevap vermeyen veya NSAil'ye bağlı yan etkilerin geliştiği orta ve/veya şiddetli ağrılarda ise, opioidler önemli bir tedavi seçeneğidir. ${ }^{[10]}$ Kronik ağrı hastalarında ağrı tedavisi uzun süre devam edeceğinden, kronik analjezik kullanımının uzun dönem etkileri önem kazanmaktadır. Opioid analjeziklerin non-opioidlere asıl üstünlügü uzun süreli tedavide tolere edilebilirliğidir. ${ }^{[11]}$ Ağrı Tedavisi Çalışma Grubu (WGPM), kronik kas iskelet sistemi ağrıları tedavisi için, kalp damar sistemi ve böbrek hastalığı olan hastalarda ve hipertansiyon gibi kardiyovasküler risk faktörü taşıyan olgularda NSAii'nin dikkatle kullanılması gerektiğini ve bu durumlarda parasetamol+tramadol gibi zayıf opiodlerin iyi bir seçenek olduğunu vurgulamaktadır. ${ }^{[12]}$

Kronik ağrıda tedavinin yetersizliği; ağrı yönetimindeki bilgi eksiklikleri, ilaç kötüye kullanım ve bağımlılık konusundaki bilgilendirme eksiklikleri ile opioidlerin yazılma ve ulaşılma sorunlarından kaynaklanabilmektedir.

Dünya Sağlık Örgütü (DSÖ)'ne göre üçüncü basamakta yer alan opioidler, elimizdeki en potent ağrı kesici ilaçlarımızdır. Bunlar kolay titre edilir ve kabul edilebilir bir risk/yarar oranı sunar. Cerrahi sonrası ağıı dahil, akut ve kansere bağlı ağrılarda kullanımı yaygındır. Kanser dışı kronik ağrıda kullanımı ise hala tartışmalıdır. ${ }^{[9]}$ DSÖ, analjezik merdiveni, kanser ağrısının farmakolojik tedavisi için geliştirilmiş olmasına rağmen, kansere bağlı olmayan kronik ağrıda da güvenle kullanılmaktadır. ${ }^{[13,14]}$ Özellikle teknolojik açıdan gelişmiş ülkelerde, KDKA'da bu opioidlerin reçetelenmesi giderek artmaktadır. Alman Sağlık Sigortası verilerine göre, günlük yazılan opiod dozu 2000 yılında 24,1 milyon iken 2010 yılında 107,6 milyonu bulmuş, üç aydan uzun süreli kullanım oranı $\% 4,3$ 'ten $\% 7,5$ 'e yükselmiştir. KDKA'da opioid kullanım etkinliğine dair kanıtlara paralel olarak, opioid kullanımı da giderek artmaktadır. Reçetelenmedeki bu artış; opioidlerin tavan etkilerinin ve organlara belirgin toksik etkilerinin olmaması, yan etkilerin sık görülmesine rağmen bu etkilerin genelde geçici olmaları, ilaç kesilmesi ile diğer non-opioidlerde gözlenenin aksine bu yan etkilerin ortadan kalkması ile açıklanabilir. ${ }^{[14]}$

Kontrollü klinik çalışmalardaki kanıtların sınırılığı, üç aydan uzun dönem kullanımlardaki etkinlik, güvenilirlilik ve tolerabilite verilerindeki yetersizlikler, bireysel endojen faktörlerle opiodlerin etkileşimi, mevcut tedavi kılavuzlarında üçüncü basamak opiodlerin KDKA'da konservatif kullanımına neden olmaktadır. ${ }^{[15,16]}$

Kronik boyun ve bel ağrısında opiod tedavisine başlama nedenleri, özetle; non-opioid analjeziklerin aşırı kullanımı, diğer tedavilere yetersiz cevap, ciddi fonksiyon kaybı ve rehabilitasyona katılımı engelleyen ciddi ağrı olarak sıralanabilir. ${ }^{[17]}$

Plasebo kontrollü çalışmalarda opioidlerin fibromiyalji (sadece tramadol), diyabetik nöropati, periferal nöropati, postherpetik nöralji, fantom güdük ağrısı, spinal kord hasarları, lomber radikülopati, osteoartrit, romatoid artrit, bel ve boyun ağrısında etkin olduğu, yaşam kalitesini arttırdıkları ve hastaların günlük fonksiyonlarında düzelmeye neden oldukları belirtilmektedir. ${ }^{[18-20]}$ Kas iskelet sisteminin nosiseptif kökenli ağrılarında ve nöropatik ağrıda, opioidler düşük ve orta düzeyde yarar sağlamaktadır. ${ }^{[18]} 2008$ yılında Amerikan Girişimsel Ağrı Derneği (ASIPP) kanser dışı kronik ağrıda tedaviyi geliştirmek ve giderek artan ilaç kötüye kullanımlarını azaltmak için bir kılavuz yayımlamış; bu kılavuzda, kanıt düzeyleri Düzey I, II (1, 2 ve 3 alt düzey) ve III olarak sınıflandırılmıştır. Düzey I güçlü kanıtları, Düzey III ise tam olarak belirlenmemiş verileri göstermektedir. Öneriler 1A dan 2C'ye kadar değişmektedir ve $1 \mathrm{~A}$ yüksek kalitede kanıta dayalı güçlü öneriler, $2 \mathrm{C}$ ise düşük / çok düşük kalitede kanıta dayalı zayıf-güçsüz önerileri içermektedir. Kılavuzda, KDKA'da opioidlerin sıkça kullanıldıkları, kısa dönemde ağrı giderilmesinde etkili olabildikleri, uzun dönem 
kullanımlarında kanıtların transdermal fentanil ve kontrollü salınımlı morfin için ılımlı (Düzey II), oksikodon için sınırlı (Düzey II-3) hidrokodon ve metadon için ise belirlenmemiş (Düzey III) olarak değişmekte olduğu belirtilmektedir. Bu kılavuzların yol gösterici olacağı, standart olmadıkları, tedavilerin hastadan hastaya, kişisel ihtiyaçlar ve tercihlere ve hatta hekimin bilgisi ve elde bulunan ilaç çeşitliliğine göre değişebileceği bilinmelidir. ${ }^{[21]}$

Furlan ve arkadaşlarının ${ }^{[9]} 2006$ yılındaki kronik ağrı çalışmalarının sonuçlarını değerlendirdikleri derlemeye göre opioidlerin;

1. Hem nosiseptif hem de nöropatik ağrıda, ağrı tedavisi ve fonksiyon düzeyini arttırmada plaseboya göre daha etki olduğu,

2. Zayıf opioidlerin KDKA tedavisi ve fonksiyon düzeyini arttırmada NSAii ve trisiklik antidepresanlardan farksız olduğu,

3. Güçlü opioidlerin NSAii ve trisiklik antidepresanlara göre ağrıda daha etkili oldukları,

4. Tramadolün, özellikle fibromiyaljide, hem ağrı giderilmesinde hem de fonksiyonların düzelmesinde etkin olduğu,

5. Klinik ve istatistiksel olarak en sık görülen yan etkilerinin konstipasyon ve bulantı olduğu (>\%10),

6. Değerlendirilen çalışmalarda opioid kötüye kullanım ve bağımlılık açısından değerlendirme kriterleri tam belirlenmediğinden sağlıklı veriler olmadığı,

7. Sadece iki çalışmada, opioid kullanan grupta plasebo grubuna göre seksüel fonksiyonlar açısından hastaların kendilerini daha iyi hissettiği, belirtilmektedir.

Kanser dışı kronik ağrıdaki farklı tutumların nedeni, tedavi hedeflerinin hekimler ve hastalarca tam olarak belirlenmemesinden de kaynaklanabilmektedir. KDKA'da tedavi hedefleri, akut ağrı veya palyatif bakıma göre çok daha kompleks ve farklıdır. Hedef; optimum derecede ağrı giderilmesi, kişilerin normal ev ve iş aktivitelerini yerine getirebilir duruma gelmeleri ve tedaviye ait en az yan etki gelişimi olmasıdır.

Otuz iki ay takip edilen 33 bel ağrısı hastasında da, ağrı ve disfonksiyon benzer şekilde azalmış, beş hasta opioid tedavisini yan etkileri nedeni ile bırakırken diğer hastaların ağrısı \%31, disfonksiyonu \%42 azalmış ve hastalarda bağımlııı gelişmediği belirtilmiştir. KDKA'da opioid tedavisi alan hastalarda, bağımlılık oranı \%24-31 olarak bulunmuş ve ilk bağımlılık davranışı 24. ayda görülmüştür. ${ }^{[1]}$
Gimbel ve arkadaşlarının daha önce opioid kullanımı ve orta-şiddetli düzeyde bel ağrısı olan hastalarda bukkal bubrenorfinin etkinliği ve tolerabilitesini araştırdıkları çalışmalarında, plasebo grubuna göre bukkal bubrenorfinin daha etkin şekilde ağrıda azalma sağladığı belirtilmiştir. Yan etkiler açısından değerlendirildiğinde, bukkal bubrenorfin grubunda konstipasyon ve kusma daha fazla görülürken, bulantı plasebo grubu ile benzer, ilaç çekilme bulguları ise plasebo grubunda daha fazla görülmüştür. Hastalarda opioide bağlı yanlış kullanım, bağımlıık, solunum depresyonu gibi bulgulara rastlanmamıştır. ${ }^{[22]}$ Alman hekimlerin, kronik bel ağrısında güçlü opioidlerin kullanımını araştırdıkları bir çalışmada; hekimlerin bu ilaçları, alternatif farmakolojik ve/veya nonfarmakolojik uygulamalar başarısız olduğunda veya riskler taşıdığında tercih ettikleri belirtilmiştir. Hastalarda yan etkiler ve tolerans gelişimine rağmen, yarar/zarar dengesi opioidlerin tercih edilmesi şeklindedir. ${ }^{[14]}$

\section{OPIOID SEÇiMi VE KULLANIM ILKELERi}

Klinik kullanımda olan opioidler; 1) kimyasal özelliklerine göre, 2) opioid reseptörleri üzerindeki etkilerine göre, 3) etki güçlerine göre sınıflandırılır. Pratik kullanımda DSÖ'nün analjezik kullanım ilkeleri ile desteklediği, etki güçlerine göre olan sınıflama kullanılmaktadır. Hafif ağrı için "zayıf etkili opioidler" (kodein, dekstropropoksifen ve tramadol), orta şiddet ve şiddetli ağrılar için "güçlü etkili opioidler" (morfin, fentanil, hidromorfon, oksikodon) kullanılmaktadır. Ülkemizde opioid seçeneklerimiz kısıtlıdır.

Opioidler öncelikle ağrısız yoldan, düşük başlangıç dozunda, düzenli saat aralıklarında ve bireyselleştirilmiş olarak verilmelidir. ilk olarak oral yol denenmelidir. Gerektiğinde non-invaziv diğer (transmukozal ya da transdermal) yollar, yeterli yanıt alınamayan hastalarda invaziv yollar (intravenöz, subkutanöz, intramusküler, epidural, intratekal, vb.) önerilir. ${ }^{[23]}$

Hastaların başlangıç tedavisi, ağı şiddeti ve kullandığı diğer ilaçlara göre düzenlenir. Hiç opioid kullanmamış hastalarda, zayıf opioid ilaçlar önerilmektedir. Analjezik merdiveninin ikinci basamağında yer alan bir opioidi belirli bir süre kullanmış hastada, güçlü opioide başlama dozu, 3-4 saatte bir 5-15 mg oral morfine eşdeğer doz olmalıdır. ${ }^{[24]}$ Gereğinde doz \%33-50 oranında arttırılarak hızlı doz titrasyonu yapılır. Kısa etki süreli opioidler, akut ağrı giderilmesi, doz titrasyonu, alevlenme ağrıları ve daha önce opioid tedavisi almamış kişilerde başlangıç doz ayarlanmasında uygun bir seçim iken; uzun etkili opioidler, günde bir veya iki kez kullanımları ile orta ve şiddetli kronik ağrı tedavisinde idamede önerilmektedir. ${ }^{[25,26]}$ 
Uzun etkili preparatlar, tolerans gelişmesini ve suistimal olasılığını azaltır. Tüm hastalarda, uygun analjezik kan düzeyini sağlayacak, "saati geldiğinde" kullanım sağlanmalıdır. Hastalara, ağrısı olmadığı halde ilacı alması gerektiğinin önemi vurgulanmalı, amacın ağrıyı kesmekten ziyade ağrının ortaya çıkmasını engellemek olduğu anlatılmalıdır. ${ }^{[24]}$ Literatürde önerilen tüm ilaçlar ve dozlar her hasta aynı olamayacağı için, tedavide bireyselleştirme önemlidir. Hastada yüksek doz opioid ihtiyacı varsa, ağrıyı açılayacak diğer patolojiler, komorbit psikiyatrik hastalık, ilaç köyüye kullanımı ve diğer stres durumları dikkatle değerlendirilmeli, ağrı raporu hazırlanmalıdır. Gereğinde girişimsel ağrı tedavisi seçeneği değerlendirilmelidir. Tedavi edilen her hastada, eşlik eden hastalıklar, organ yetmezliği ve çoklu ilaç kullanımı sorgulanmalıdır. Düzenli aralıklarla, hastanın tedaviye uyumu, ilaçların etkinliği ve yan etkiler kontrol edilmelidir. ${ }^{[27]}$

Kanada kılavuzu, KDKA tedavisi için "hafif ve orta dereceli ağrıda" birinci sıra tercih kodein veya tramadol, ikinci sıra tercih morfin, oksikodon veya hidromorfon; "şiddetli ağrıda" ise birinci sıra tercih morfin, oksikodon veya hidromorfon, ikinci sıra tercih fentanil ve üçüncü sıra tercih olarak metadon önerilmektedir. ${ }^{[18]}$

Bu derlemede, ülkemizde bulunan zayıf ve güçlü opioidlerden kısaca bahsedilecektir.

\section{Tramadol}

Tramadol hidroklorid, hem opioid hem de nonopioid özelliğe sahip, sentetik yapıda santral etkili bir analjeziktir. Opioid reseptör afinitesi düşüktür. Noradrenalin ve seratonin geri alınımını inhibe eder, nöronal seratonin salınımını arttırır. ${ }^{[28]}$ Böylece endojen analjezi sistemini, hem opioid agonist mekanizma hem de monoaminerjik etkisi ile potansiyelize etmektedir. Bu nedenle, nöropatik ağrı tedavisinde de kullanılır. Diğer opioidlere göre daha az konstipasyon, sedasyon ve immünsupresyon yapması, solunum depresyonu yapmaması, bağımlılık potansiyelinin düşük olması nedeniyle, kanser dışı kronik ağrı tedavisinde yaygın olarak kullanılmaktadır. ${ }^{[29]}$ Yüksek doz ve bağımlılık riski, diğer güçlü opioidlere göre daha azdır. Fakat, bu riskin hiç olmadığı söylenemez. Tramadol, geçmişte ilaç kötüye kullanımı ve bağımlıık riski olmayanlarda bile bağımlılığı tetikleyebilir. Yüksek dozlarında, solunum sayısını azaltabilir ve konvülziyon eşiğini düşürebilir. ${ }^{18]}$

$\mu$ (mü) reseptörüne afinitesi morfinden ve kodeinden daha düşük olmakla birlikte, aktif metabolitinin afinitesi tramadolden 5-6 kat daha fazladır. Oral biyoyararlanımı yüksektir, hızla absorbe olur. Oral alımdan sonra yaklaşık iki saatte maksimum kan seviyesine ulaşır. ${ }^{[28]}$
Serotonin düzeyini arttıran ilaçlarla (SSRI gibi) beraber kullanımlarında ve konvülziyon riski olan hastalarda nöbetlere neden olabilir. ${ }^{[18]}$ Tramadol, karaciğerde metabolize olur ve böbrekle atılır. Hepatik ve renal yetmezliği olanlarda ve yaşıllarda doz azaltılmalıdır. En sık görülen yan etkileri; bulantı, kusma, baş dönmesi, sedasyon, ağız kuruluğu, halsizlik, terleme ve ortostatik hipotansiyondur. Doz titrasyonu, yan etkileri azaltır. ${ }^{[28]}$

Tramadolün, osteoartrite bağlı orta şiddetteki ağrılarda etkin, şiddetli ağrılarda ise kısıtlı düzeyde etkili olduğunu belirtilmektedir. ${ }^{[30]}$ Opiod kullanan hastalarda görülebilen düşmelere bağlı kırıklar, tramadol kullanımında daha azdır. ${ }^{[31,32]}$

\section{Kodein}

Doğal bir fenantren türevidir ve mü reseptörüne düşük afinite gösterir. ${ }^{[33]}$ Kodeinin etkisi morfinin etkisinin yaklaşık onda biri kadardır. Oral biyoyararlanımı yüksektir. Metabolitleri analjezik etkiye katkı sağlayabilir. Aktif metabolitleri birikeceğinden böbrek yetmezliğinde kullanılmamalıdır. Kodein etkili bir antitussiftir ve öksürüğü baskılar. Diğer opioidlerle kıyaslandığında bulantı-kusma yan etkisi daha fazladir. ${ }^{[29]}$

Zayıf opioidler düşük bağımlılık riski nedeni ile hafif ve orta şiddetli ağrılarda, özellikle yaşılıarda, sıkça kullanılmaktadır.

Güçlü opioidlerden morfin, hidromorfon, oksikodon ve fentanil ülkemizde ulaşabildiğimiz ajanlardır. Fakat her formülasyonları bulunmamaktadır.

\section{Morfin}

Morfin hala altın standarttır, güçlü bir $\mu$ reseptör agonistidir. Etkinliği, güvenilirliği, ucuz olması ve birçok formda çeşitli yollardan uygulanabilmesi nedeniyle, en çok tercih edilen opioiddir. Morfinin kendisi dışında aktif metaboliti morfin 6-glukronid de, $\mu$ reseptörüne bağlanması ve kolaylıkla kan-beyin bariyerini geçmesi ile, analjezik etkinlikte yardımcı olmaktadır. Oral biyoyararlanımı, kişiler arasında belirgin farklılık gösterir. Karaciğerde metabolize olan morfin ve metabolitleri, böbrek yolu ile atılır. Illeri dönem hepatik yetmezliklerde eliminasyonun azalacağı unutulmamalı ve böbrek yetmezlikli hastalarda dikkatli olunmalıdır. Özellikle yaşılıarda, renal fonksiyonlarda gerileme ve dehidratasyon gibi durumlarda, morfinin ağrı kesici etkisinden sorumlu olan aktif morfin 6-glukronit birikebilir ve toksik reaksiyonlara neden olabilir. ${ }^{[34]}$

Morfinin orta düzey dozu (195 mg/gün) ile altı yıla kadar uzun süreli tedavi bildirilmiştir. Orta dozlar ile 
kognitif fonksiyonların etkilenmediği, fakat doz arttırımı için yedi günlük aralığa ihtiyaç olduğu belirtilmektedir. Başlangıç için, genellikle $5 \mathrm{mg} / 4$ saat dozları önerilir. Daha önce düzenli zayıf opiod alanlarda bu doz $10 \mathrm{mg} / 4$ saat şeklinde ayarlanabilir. Amaç en azından ağrıların \%30 azalması şeklinde olmalıdır. Çoğu hastada $200 \mathrm{mg} /$ gün doz yeterli olur. Yaşlıların tedavisinde, erişkin dozlarının \%50'sinin kullanılması gerektiği bildirilmektedir. ${ }^{[18]}$

Bel-boyun ağrısı, baş ağrısı, dejeneratif disk hernisi, başarısız bel cerrahisi, radikülonöropatiler gibi kronik ağrıları olan 68 hastalık bir grupta, uzun dönem kontrollü salınımlı morfinin etkileri araştırılmış; bel ve boyun ağrısında günlük ortalama opioid kullanımı, sırası ile $81,5 \mathrm{mg}$ ve $76,2 \mathrm{mg}$ olarak hesaplanmıştır. Hastalar, ortalama bir yıl süre ile tedavi almışlar ve \%66,2'si yan etki bildirmezken, \%20 ,6'sında konstipasyon ve \%5,9'unda uyku bozukluğu bildirilmiştir. ${ }^{[35]}$

\section{Hidromorfon}

Hidromorfon, analjezik etkinliğini $\mu$-opioid reseptörleri yolu ile gösteren, yarı sentetik bir opioiddir. Oral hidromorfon, aynı yoldan alınan morfine göre 5-8 kat daha güçlü etkiye sahiptir. Diğer pek çok ilaçtan farklı olarak, sitokrom p-450 yolağını kullanmaması, daha az ilaç etkileşimine yol açar. Bu özelliği, yaşlılarda ve çoklu ilaç kullanımı olan kişilerde hidromorfonun güvenli bir seçenek olmasını sağlar. ${ }^{[36]}$ Morfine kıyasla, ilaç kötüye kullanım oranı daha fazladır. ${ }^{18]}$

Hidromorfon, aktifbir metabolit olan morfin 6-glukronite sahip değildir. Bu da, özellikle renal kapasitesi sınırlı olan yaşılarda avantajdır. Nöroeksitatör bir metabolit olan hidromorfon 3-glukronit nedeni ile, yüksek doz hidromorfon tedavisi alanlarda, allodini, miyoklonus ve konvülziyonlar bildirilmiştir. ${ }^{[37]}$ Hidromorfon plazma proteinlerine düşük oranda bağlandığından, ileri yaş, kronik hastalıklar ve malnütrisyon gibi düşük serum albümin seviyesi ile giden durumlarda, serbest ilaç konsantrasyonunda minimal değişikliğe neden olur. Bu da, hidromorfonun yaşlılarda tercih edilmesinde önemli faktörlerdendir. ${ }^{[38]}$

Kronik bel ağrısı için hidromorfon kullanılan ve hastaların altı ay boyunca takip edildiği bir çalışmada, hidromorfonun etkin ve güvenilir olduğu, uyku kalitesini arttırdığı belirtilmiştir. ${ }^{[38]} \mathrm{Bu}$ çalışma altı ayla sınırlandırıldığı için, uzun dönem etkiler açısından araştırılmalıdır.

\section{Oksikodon}

Tebainden elde edilen, yarı sentetik bir opioid agonistidir. $\mu$ ve $\kappa$ (kappa) reseptörlerine bağlanarak etkisini gösterir. ${ }^{[34]}$ Oksikodonun; titre edilebilmesi, etkisinin hızlı başlaması, aktif metabolitinin olmaması, yarılanma ömrünün kısa olması, etki süresinin uzun olması ve yan etkilerinin az olması, avantajlarıdır. ${ }^{[33]}$

Oksikodonun kontrollü formları, morfine göre daha hızlı etki gösterir ve iki saat boyunca stabil bir analjezi sağlar. Morfin gibi mental durumda değişikliklere ve sedasyona yol açmadığından, oksikodon yaşlılarda iyi bir alternatif olabilir. Oksikodon ve hidromorfon, doz azaltılması ile böbrek ve karaciğer fonksiyonları kısıtlanmış yaşlılarda güvenli seçimler olarak gözükmektedir. ${ }^{[17]}$ Fakat, oksikodon karaciğerde oksimorfona dönüşür; böbrek yetmezliğin durumunda, birikerek santral sinir sistemi toksisitesine yol açar. ${ }^{[34]}$ Bu açıdan dikkatli olunmalıdır. Morfine kıyasla, ilaç kötüye kullanım oranı daha fazladır. ${ }^{[18]}$

\section{Fentanil}

Fentanil, yarı sentetik fenilpiperidin türevi olup, güçlü bir $\mu$ reseptör agonistidir. Morfinden 75-100 kat daha kuvvetlidir. Transdermal formları kronik ağrıda kullanılmaktadır. Transdermal emilim hızı, flasterin yapıştırıldığı derinin terlemesi ve Isısı, derinin altındaki kasın kitlesi ve yağ deposu gibi kişisel farklılıklarda, doz titrasyonunda zorluklar meydana getirmektedir. ${ }^{[33]}$ Fentanil, histamin salınımına neden olmadığı gibi, miyokard kontraktilitesinde ya çok az değişiklik olur ya da hiç olmaz. Böbrek yetmezliğinde kullanılabilir, ancak kümülatif etkileri açısından kontrol edilmelidir. ${ }^{[39]}$

Transdermal fentanilin, nosiseptif, nöropatik ve mikst tipteki kronik orta derecede ve şiddetli ağrılarda etkili olduğu, uyku ve yaşam kalitesini arttırdığı gösterilmiştir. ${ }^{[40]}$

Kolay uyum sağlanan ve daha az konstipasyona neden olan, transdermal fentanil, bulantı ve/veya kusması olan, oral alımı sorunlu hastalarda kullanım avantajına sahiptir.

\section{Meperidin}

Aktif metaboliti olan normeperidinin birikimi sonucu hastada konvülziyon nöbetlerine neden olan meperidinin uzun süreli kullanımına bağlı olarak, sedasyon artışı ve psikomimetik aktivite gelişir. Meperidin, bu etkilerinden dolayı kronik ağrıda kullanılmaz. ${ }^{34]}$

\section{OPIOID KULLANIMINA BAĞLI YAN ETKILER}

Opioidlere bağlı olarak, bulantı ve kusma, konstipasyon, solunum depresyonu, sedasyon, mental durum ve kognitif fonksiyon bozukluğu, miyoklonus, hiperaljezi ve allodini, nörotoksisite, kaşıntı, idrar retansiyonu, 
sıvı retansiyonu, ağız kuruluğu, non-kardiyojenik pulmoner ödem, immün sistem baskılanması, endokrin sistem etkileri, tolerans, fiziksel ve psişik bağımlılık gibi pek çok yan etki görülmektedir. Oral yoldan opioid alan kişilerin \%51'i en az bir yan etki ile karşılaşmış ve $\% 20$ 'si yan etki veya komplikasyon nedeni ile ilacı kesmek zorunda kalmıştır. ${ }^{[41]}$ Opioidlerin uzun süreli kullanımlarında, etkinliğin sınırlı olduğu ve yan etkiler nedeni ile tedavi devamının güçleştiği, hastaların ancak \%40 kadarının (7-24 ay tedavide) tedaviyi sürdürebildiklerini bildiren yayınlar mevcuttur. ${ }^{[21]}$ Uzun süreli kullanımlarında, yaş ve cinsiyete bağlı değişebilen faktörler, yararlar ve olası yan etkiler konusundaki bilgilerimiz oldukça azdır. Oysa, kronik ağrı tedavisinde uzun süreli kullanımlara daha fazla ihtiyaç duyulmaktadır. Subjektif olan yan etkilerin görülme sıklığında birçok faktör rol oynamaktadır. Yan etkiler; kullanılan opioide, uygulama yoluna, doza ve hastanın kişisel ve genetik farklılığına bağlı olarak değişiklik gösterir. ${ }^{[29]}$ Örneğin; kötüye kullanım ve bağımlılık riski genç erkeklerde daha fazla iken, düşmeye bağlı kemik kırıkları yaşlı kadın cinsiyette daha fazla görülmektedir. ${ }^{[42]} \mathrm{Bu}$ tür riskleri azaltmak için en önemli başlangıç, uzun dönem opioid kullanımında yaş ve cinsiyete göre risklerin değişebileceğini bilmek ve tedaviyi bireyselleştirmektir.

Uygulama yolu da yan etkilerin görülmesini etkilemektedir. Kronik kullanımda yan etki olasılığı en yüksek uygulama yolu, oral yoldur. Subkutan ve rektal uygulama, oral morfine göre daha az bulantı ve kusmaya neden olur. ${ }^{[29]}$ Transdermal uygulamalarda da, oral yola göre daha az yan etki görülür. Transdermal fentanil kullanımında daha az konstipasyon görülür. ${ }^{[43]}$

Yan etki gelişimi için, predispozan faktörler de önemli rol oynamaktadır. Kişisel ve genetik farklılıklar, opioidlere karşı hassasiyeti etkiler. ${ }^{[42]}$ Yaş, ırk ve cinsiyet önemlidir. Bulantı ve kusma, zencilerde beyazlardan, iştahsızlık, ağız kuruluğu, kaşıntı ve bulantı isekadınlarda erkeklerden daha fazla görülür. ${ }^{[4]}$ Miyoklonus ve üriner problemler gençlerde daha fazladır. Konstipasyon, ağız kuruluğu ve halusinasyon yaşla beraber artar. Yaşla birlikte renal fonksiyonların bozulması, opioid ve metabolitlerinin birikmesine yol açabilir. Bu nedenle, yaşlı hastalarda doz azaltılmalı ve doz aralıkları uzatılmalıdır. ${ }^{[45]}$

Bel ağrısı nedeni ile opioid kullanan erkeklerde, opioid kullanmayan erkeklere ve opioid kullanan kadınlara göre daha fazla depresyon ve affektif bozukluğa rastlanmıştır. ${ }^{[46]}$

Kronik opioid kullanımı, endokrin sistemi etkilemekte, stres hormonlarının salınımını azaltmakta, luteyinize hormon (LH), follikül-stimüle edici hormon (FSH), $A C T H$ ve $\beta$-endorfin salınımını azaltmaktadır. Seksüel disfonksiyon, en sık görülen yan etkidir; sıklıkla impotens ve libido azalması tanımlanır. ${ }^{[47]}$ Hastaya, bu etkinin geri dönüşümlü olduğu hakkında bilgi verilmelidir. Premenopozal dönemdeki kadınlarda, amenore ve düzensiz menstruel siklus olabilir.

\section{Tolerans, Fiziksel ve Psişik Bağımlılık}

Tolerans, fiziksel ve psişik bağımlılık, ağrı tedavisinde oldukça önemli konulardır. Sıklıkla birbirine karıştırılmakta, bağımlılık korkusu ile hastalar yeterli tedavi edilmemektedir. ${ }^{[48,49]}$

\section{Tolerans}

Tekrarlanan uygulamalarda aynı analjezik yanıtı elde etmek için, doz artışına gereksinim duyulmasıdır. ${ }^{[50]}$ Kronik opioid kullanımında, hangi yol kullanılırsa kullanılsın, tolerans gelişir. Oral veya transdermal uygulamalarda, aralıklı parenteral uygulamalara göre daha yavaş tolerans gelişir ve analjezik etkinlik daha uzun süre korunur. Tolerans gelişiminde kullanılan opioid de önemlidir. ${ }^{[51]}$ Kanser-dışı kronik ağrısı olan hastalarda, uzun süreli opioid kullanımında analjeziye karşı tolerans gelişmemektedir. ${ }^{[49]}$ Tolerans sorun olmaya başladığında veya opioid dozundaki artışlar yan etkilere neden oluyorsa, alternatif bir opioid kullanılmalıdır. ${ }^{[52]}$

\section{Fiziksel bağımlılık}

Kronik kullanılan opioidin farmakolojik etkisine fizyolojik cevaptır. Düzenli kullanılan ilacın aniden kesilmesine, dozun hızlı azaltılmasına, agonist opioid etkisindeki hastaya agonist-antagonist veya antagonist verilmesine bağlı olarak, santral nöradrenerjik ve sempatik sistemde hiperaktivite ile görülen geri çekilme bulgularıdır. Bunlar; esneme, burun akıntısı, terleme, göz yaşarması, ajitasyon, titreme, ateş, taşikardi, hiperventilasyon, hipertermi, midriyazis, bulantı-kusma, diyare, karın ve kas krampları şeklindedir. ${ }^{[53]}$ Fiziksel bağımlıı̆̆ın gelişmesi, genelde 3-4 hafta kullanımdan sonra beklenir. Kısa etki süreli opioidlerle, daha kısa sürede fiziksel bağımlılık gelişmektedir. ${ }^{[33]}$ Tolerans ve fiziksel bağımlııı, geriye dönebilen süreçlerdir.

\section{Psikolojik bağımlılık (addiksiyon)}

İlacın psişik ve mental etkileri için kullanılan, ısrarcı-ilaç-kullanma davranışı ile karekterize, biyo-psikososyal bir hastalıktır. Psikolojik bağımlılı̆̆ı olanların, fiziksel bağımlılığının da olması muhtemeldir. Analjezi için opioidlerin yeterli düzeyde kullanılmamasının en önemli nedenlerinden biri, psikolojik bağımlılık korkusudur. Genetik yatkınlık, ilacın kronik kullanımı, alkol bağımlılığı, hoş olmayan psikososyal faktörler, bağımlılık oluşmasında önemli unsurlardır. Psikolojik 
bağımlılığı olanların ilaç kullanımında kontrol bozulmuştur. Hastalar, ilacı bulmak ve kullanmak için karşı konulmaz istek duyarlar ve yan etkiler ortaya çıssa bile ilacı kullanırlar. Opioid tedavisine başlayacak hastalar dikkatlice irdelenmeli ve tedaviye başlarken psikolojik değerlendirmenin önemi unutulmamalıdır. ${ }^{[54]}$ Opioid tedavisi alan kronik ağrılı bir hasta akut ağrı ile gelirse, bağımlılık bulguları açısından da mutlaka değerlendirilmelidir.

\section{Opioid Kötüye Kullanımı-Bağımlılık}

KDKA'da, opioid kullanımı sırasında bağımlılık oranını belirleyebilmek için değişik risk skalaları kullanılsa da, hangi hastaların bağımlılık geliştirebileceğini tahmin etmek güçtür. ${ }^{[18]}$ En çok tercih edilen skala, Opioid Risk Tool (ORT)'dur. ${ }^{[1]}$ Bağımlılık riskinin belirlenmesinde en güçlü prediktör; hastanın önceki alkol, kokain ve ilaç kullanım öyküsü ile bu nedenlerle olmuş olan mahkumiyet öyküsüdür. ${ }^{[18,21]}$ Opioid kötüye kullanımı, psikiyatrik bozuklukları olan hastalarda daha sıktır. ${ }^{[55]}$ Tüm hastalarda olduğu gibi bu hastalarda da, iyi tanımlanmış somatik veya nöropatik ağrıda, opioidler reçete edilmelidir. Bu hastalarda ayrıca, yavaş titrasyon, sıkı ve ayrıntılı takip gerekir.[18]

Erkekler, genç yetişkinler ve yüksek doz opioid reçetelenen kişilerde, opioid yanlış kullanımı daha fazladır. Genç popülasyon ile karşılaştırıldığında, 65 yaş üstü kişilerde ilaç kötüye kullanım insidansı 10 kat daha az bulunmuştur. ${ }^{[56]}$ KDKA'sı için opioid tedavisi alan hastalarda bağımlılık oranı \%24-31 olarak belirtilmektedir. ${ }^{[1]}$ Yüksek doz (120 mg/gün morfin veya eşdeğer dozda bir başkası) opioidlerin kullanımında, hastanın yazılı onayı ve periodik değerlendirmeleri yapılmalı, bir ağrı uzmanından destek alınmalıdır.

Opioid tedavisinde başarı, yan etkilerin tedavisine bağlıdır. Yan etkilerin tedavisinde Avrupa Palyatif Bakım Derneğinin (EAPC) önerdiği; 1) dozun azaltılması, 2) uygulama yolunun değiştirilmesi, 3) yan etkilerin semptomatik tedavisi ve 4) opioidin değiştirilmesi, şeklinde dört genel yaklaşım vardır. ${ }^{[44]}$

\section{OPIOID TEDAVISI VE ÖNLEMLER}

Opioid tedavisine başlamadan önce, hasta ve hekim, tedavi beklentilerini ve hedeflerini belirlemelidir. Hedef, çoğu zaman ağrının ve fonksiyon kaybının tamamen ortadan kalkması değildir; ağrı şiddetinin en azından \%30 azalması ve fonksiyonlarda düzelme şeklinde olabilir. Hekim, hastanın hedeflerinin gerçekçi olması konusunda yardımcı olmalıdır. Belirlenen hedefler hastanın dosyasına ve alınmış ise, opioid kontratına kaydedilmelidir. Bu hedefler daha sonra tedavinin etkinliğini ölçmede kullanılabilir. Hastalar ile, tedavi öncesi ayrıntılı olarak tedavi riskleri konuşulmalı ve bu ilaçları kullanırken sorumluluk taşıdıklarının bilincinde olmaları sağlanmalıdır. ${ }^{[1,18]}$ Gelişebilecek komplikasyonlar, özellikle de uzun dönem etkileri (uyku apnesi, hipogonadizm, amenore, opioid hiperaljezisi) ve tedavi planları hakkında hasta bilgilendirilmelidir.

Özellikle opioidlerin uzun dönem kullanımlarında, opioid kontratları sıkça kullanılmaktadır. Hekimin hastayı tanımadığı ve kötüye kullanım riskinin olduğu zaman, bunlar tercih edilebilir. Bu sözleşmeler, hasta uyumunu arttırmakta ve uyumsuzluk halinde opioid tedavisini kesmede yardımcı olur. ${ }^{[57,58]}$

KDKA tedavisinde, optimal opioid dozun belirlenmesi çok önemlidir. Tedaviye düşük dozlarda başlanılması, küçük miktarda arttırımlar ve dikkatli titrasyon önerilir. Özellikle yaşlı hastalar ve riskli hastalar, tedavinin üçüncü gününde etki ve sedasyon gibi yan etkiler için kontrol edilmelidir. Opioid etkinliği, fonksiyonlardaki (günlük aktiviteler, uyku durumu, yürüme kabiliyeti, sosyal aktivitelere katılım) düzelme veya ağrı şiddetinde \%30 azalma ile belirlenebilir. Gelişen kompilikasyonlar, kontrol edilebilir nitelikte olmalıdır. Optimal doza ulaşıldığında veya başarısız olunduğunda (başarısız ağrı tedavisi, kötüye kullanım veya bağımlılık), titrasyon sonlandırılır. Tüm bu durumlar, hasta dosyasına ayrıntılı olarak kaydedilmelidir. KDKA'da, genellikle 200 $\mathrm{mg} /$ gün morfin ve eşdeğer dozdaki opioidlerle amaca ulaşılabilir. Daha yüksek dozlarda hasta, yan etkiler, opioid etkisizliği açısından sıkça gözlenmeli ve kötüye kullanım olasılıkları değerlendirilmelidir. ${ }^{[18]}$

KDKA için opiod kullanan ve bağımlı olan kişilerde, “opioid tedavisi yeniden yapılandırılmalı", "metadon veya bubrenorfin tedavisi" planlanmalı veya "yoksunluk-bazlı tedaviler" düşünülmelidir. Yeniden opioid planlanmasında, mümkünse oksikodon ve hidromorfondan sakınılarak, $200 \mathrm{mg} /$ gün morfin veya eşdeğer dozundan yüksek dozda olmayacak opioid, ağrı tedavisinde ve bağımlılık tedavisinde uzman bir hekimin sıkı kontrolünde, tedaviye hastane veya tedavi ünitesinde başlanmalıdır. Hastanın eğitilmesi, tedavi sözleşmesi, idrar analizleri, mutlaka sağlanmalıdır. ${ }^{[18]}$ Bu şartlarla, opioid kötüye kullanımının \%50 azaldığı belirtilmektedir. ${ }^{[59]}$

KDKA'da opioid kesilme kriterleri; ağrıda yetersiz azalma, tolere edilemeyen yan etkilerin görülmesi, kontrol edilemeyen doz artışı, ilacın kural dışı kullanı$\mathrm{mı}$, hastanın aktivitesinde artış sağlanamaması ve doktor değişimi olarak özetlenebilir. ${ }^{[18,21,41]}$

Sonuç olarak; KDKA'da opioidler düşük dozlarda kullanılmaya çalışıımalı, yüksek dozların reçete edilmesi gerekiyorsa, mutlaka ağrı uzmanına danışılmalıdır. Opioidlerin kullanımı uzun süreli non-opioidlere bağlı 
gastrik ve renal toksisiteyi azaltırken, opioid tedavisi alan kronik ağrılı hastalarda bağımlılık riski atlanmamalıdır. Hasta ile tedavi hedeflerinin belirlenmesi, kontratların imzalanması, düzenli aralıklarla yapılan kontroller, bağımlılık gelişmemesi için benimsenmesi gerekli tedavi stratejileridir. Günümüzde KDKA için sorumuz; "Opioidleri kullanmalı mıyız?" değil, "Opioidleri etkin kullanmak, güvenliliği arttırmak, yan etkileri ve yanlış kullanımları azaltmak için neler yapmalıyız?" olmalıdır.

\section{KAYNAKLAR}

1. Marcus AD. In: Opioids in Chronic Pain. Marcus AD, editor; Chronic Pain. A Primary Care Guide to Practical Management. Totowa, New Jersey: Humana Press Inc.;2005. p.269-87.

2. Côté P, Cassidy JD, Carroll L. The treatment of neck and low back pain. who seeks care? who goes where? Med Care 2001;39(9):956-67.

3. Webb R, Brammah T, Lunt M, Urwin M, Allison T, Symmons D. Prevelance and predictors of intense chronic and disabling neck and back pain in the UK general population. Spine (Phila Pa 1976) 2003;28(11):1195-202.

4. Potter M, Schafer S, Gonzale-Mendez E, Gjeltema K, Lopez A, Wu J, Pedrin R, Cozen M, Wilson R, Thom D, CroughanMinihane $M$. Opioids for chronic non-malignant pain: attitudes and practices of primary care physicians in the UCSF/Stanford Collaborative Research Network. J Fam Pract 2001;50(2):145-51.

5. Gouveia N, Rodrigues A, Ramiro S, Eusébio M, Machado PM, Canhão H, Branco JC. The Use of Analgesic and Other Pain-Relief Drugs to Manage Chronic Low Back Pain: Results from a National Survey. Pain Pract 2016. [Epub ahead of print] Crossref

6. Shah D, Anupindi VR, Vaidya V. Pharmacoeconomic Analysis of Pain Medications Used to Treat Adult Patients with Chronic Back Pain in the United States. J Pain Palliat Care Pharmacother 2016;30(4):300-7. Crossref

7. Segasothy M, Chin GL, Sia KK, Zulfiqar A, Samad SA. Chronic nephrotoxicity of anti-inflammatory drugs used in the treatment of arthritis. $\mathrm{Br} \mathrm{J}$ Rheumatol 1995;34(2):162-5.

8. Altman RD, Smith HS. Opioid therapy for osteoarthritis and chronic low back pain. Postgrad Med 2010;122:87-97. Crossref

9. Furlan AD, Sandoval JA, Mailis-Gagnon A, Tunks E. Opioids for chronic non-cancer pain: a meta-analysis of effectiveness and side effects. CMAJ 2006;174(11):1589-94.

10. Infante-Rivard C, Lortie M. Prognostic factors for return to work after a first compensated episode of back pain. Occup Environ Med 1996;53(7):486-94.

11. Schnitzer JT. Update on guidelines for the treatment of chronic musculosketal pain. Clin Rheumatol 2006;25 Suppl 1:S22-9.

12. World Health Organization. WHO's cancer pain ladder for adults. Available from: http://www.who.int/cancer/ palliative/painladder/en

13. Bruntsch $U$. drug therapy of chronic pain. A practical approach. MMW Fortschr Med 1999;141(42):30-2.
14. Ueberall M, Eberhart A, Mueller-Schwefe GHH. Physicians Experience with and Expectations of the Safety and Tolerability of WHO-Step III Opioids for Chronic (Low) Back Pain: Post Hoc Analysis of Data From a German CrossSectional Physician Survey. Pain Reaserch and Treatment 2015. Crossref

15. Chou R, Fanciullo GJ, Fine PG, Adler JA, Ballantyne JC, Davies P, Donovan MI, Fishbain DA, Foley KM, Fudin J, Gilson AM, Kelter A, Mauskop A, O'Connor PG, Passik SD, Pasternak GW, Portenoy RK, Rich BA, Roberts RG, Todd KH, Miaskowski C; American Pain Society-American Academy of Pain Medicine Opioids Guidelines Panel. Clinical guidelines for the use of chronic opioid therapy in chronic noncancer pain. J Pain 2009;10(2):113-30. Crossref

16. Häuser W, Bock F, Engeser P, Hege-Scheuing G, Hüppe $M$, Lindena G, Maier C, Norda H, Radbruch L, Sabatowski R, Schäfer M, Schiltenwolf M, Schuler M, Sorgatz H, Tölle T, Willweber-Strumpf A, Petzke F. Recommendations of the updated LONTS guidelines. Long-term opioid therapy for chronic noncancer pain. Schmerz 2015;29(1):109-30. Crossref

17. Pergolizzi J, Böger RH, Budd K, Dahan A, Erdine S, Hans G, Kress HG, Langford R, Likar R, Raffa RB, Sacerdote P. Opioids and the management of chronic severe pain in the elderly: consensus statement of an international Expert Panel with focus on the six clinically most often used World Health Organization Step III opioids (bubrenorphine, fentanyl, hydromorphone, methadone, morphine, oxycodone) Pain Pract 2008;8(4):287-313. Crossref

18. Canadian Guideline for Safe and Effective Use of Opioids for Chronic Non-Cancer Pain. Recommendations for Practice, 2010. Available from: http://nationalpaincentre.mcmaster. ca/opioid/

19. Furlan AD, Pennick V, Bombardier C, Van Tulder M; Editorial Board, Cochrane Back Review Group. 2009 updated method for systematic reviews in the Cochrane Back Review Group. Spine (Phila Pa 1976) 2009;34(18):1929-41. Crossref

20. Eisenberg E, McNicol ED, Carr DB. Efficacy and safety of opioid agonists in the treatment of neuropathic pain of nonmalignant origin: systematic review and meta-analysis of randomized controlled trials. JAMA 2005;293(24):3043-52.

21. Trescot AM, Helm S, Hansen H, Benyamin R, Glaser SE, Adlaka R, Patel S, Manchikanti L. Opioids in the management of chronic non-cancer pain: an update of American Society of the Interventional Pain Physicians' (ASIPP) Guidelines. Pain Physician 2008;11(2 Suppl):S5-62.

22. Gimbel J, Spierings EL, Katz N, Xiang Q, Tzanis E, Finn A. Efficacy and tolerability of buccal buprenorphine in opioidexperienced patients with moderate to severe chronic low back pain: results of a phase 3 , enriched enrollment, randomized withdrawal study. Pain 2016;157(11):2517-26. Crossref

23. Portenoy RK, Ahmed E. Principles of opioid use in cancer pain. J Clin Oncol 2014;32(16):1662-70. Crossref

24. Ripamonti Cl, Santini D, Maranzano E, Berti M, Roila F; ESMO Guidelines Working Group. Management of cancer pain: ESMO Clinical Practice Guidelines. Ann Oncol 2012;23 Suppl 7:vii139-54.

25. Kalso E, Allan L, Dellemjin PL, Faura CC, Ilias WK, Jensen TS, Perrot S, Plaghki LH, Zenz M. Recommendations for using opioids in chronic non-cancer pain. Eur J Pain 2003;7(5):381-6. 
26. Ross EL, Hahn K. KADIAN (morphine sulfate extendedrelease) capsules for treatment of chronic, modorate-tosevere, nonmalignant pain. Int J Clin Pract 2008;62(3):4719. Crossref

27. Auret K, Schug SA. Pain management for the cancer patient current practice and future developments. Best Pract Res Clin Anaesthesiol 2013;27(4):545-61. Crossref

28. Leppert W. Tramadol as an analgesic for mild to modorate cancer pain. Pharmacol Rep 2009;61(6):978-92.

29. Tuncer S. Kanser Ağrısı ve Farmakolojik Tedavi. İçinde: Köknel Talu G, editör. Kanser Ağrısı. İstanbul: Bilimsel Tıp; 2010. p.67-118.

30. Cepeda MS, Camargo F, Zea C, Valencia L. Tramadol for osteoarthritis: a systematic review and metaanalysis. J Rheumatol 2007;34(3):543-55.

31. Solomon DH, Rassen AJ, Glynn RJ, Garneau K, Levin R, Lee J, Schneeweiss S. The comperative safety of opioids for nonmalignant pain in older adults. Arch Intern Med 2010;170(22):1979-86. Crossref

32. Vestergaard P, Rejnmark L, Mosekilde L. Frakture risk assocated with the use of morphine and opiates. J Intern Med 2006;260(1):76-87.

33. Keskinbora K. Opioid Analjezikler. İçinde: Erdine S. editör. Ağrı, 3. baskı. İstanbul: Nobel Tıp Kitabevleri; 2007. p.581-604.

34. Christo PJ, Mazloomdoost D. Cancer pain and analgesia. Ann N Y Acad Sci 2008;1138:278-98. Crossref

35. Chao J. Retrospective analysis of Kadian (morphine sulfate sustained-release capsules) in patients with chronic, nonmalignant pain. Pain Med 2005;6(3):262-5

36. Lussier D, Richarz U, Finco G. Use of hydromorphone, with particular reference to the OROS formulation, in the elderly. Drugs Aging 2010;27(4):327-35. Crossref

37. Thwaites D, McCann S, Broderic P. Hydromorphone neuroexcitation. J Palliat Med 2004;7(4):545-50.

38. Wallace $M$, Thipphawong J. Open-label study on the londtherm efficacy, safety, and impact on quality of life of OROS hydromorphone ER in patients with chronic low back pain. Pain Med 2010;11(10):1477-88. Crossref

39. Aşık I. Kanser Ağrı Tedavisi. İçinde: Tüzüner F, editör. Anestezi, Yoğun Bakım. Ağrı. Ankara: Özyurt Matbaacılık; 2010. p.1613-35.

40. Park JH, Kim JH, Yun SC, Roh SW, Rhim SC, Kim CJ, Jeon SR. Evaluation of efficacy and safety of fentanyl transdermal patch (Duragesic D-Trans) in chronic pain. Acta Neurochir 2011;153(1):181-90. Crossref

41. Feinberg S, Provenzano D, Bertagnolli A, et al. ACPA Consumer Guide to Chronic Pain Medication and Treatments, American Chronic Pain Association, Inc. 2011. Available from: http:// www.theacpa.org

42. Campell $\mathrm{Cl}$, Weisner $\mathrm{C}$, Leresche L, Ray GT, Saunders $\mathrm{K}$, Sullivan MD, Banta-Green CJ, Merrill JO, Silverberg MJ, Boudreau D, Satre DD, Von Korff M. Age and gender trends in long-term opioid analgesic use for noncancer pain. Am J Public Health 2010;100(12):2541-7. Crossref

43. Aydınlı I. Kanser Ağrısı. Klinik Gelişim 2004;17(3-15).
44. Swegle JM, Logemann C. Management of common opioid-induced adverse effects. Am Fam Physician 2006;74(8):1347-54.

45. Forman WB. Opioid analgesic drugs in the elderly. Clin Geriatr Med 1996;12(3):489-500.

46. Fillingim RB, Doleys DM, Edwards RR, Lowery D. Clinical characteristics of chronic back pain as a function of gender and oral opoid use. Spine (Phila Pa 1976) 2003;28(2):143-50.

47. Cole BE. Neuroendocrine implications of opioid therapy. Curr Pain Headache Rep 2007;11(2):89-92.

48. Kalso E, Edwards JE, Moore RA, McQuay HJ. Opioids in chronic non-cancer pain; systematic review of efficacy and safety. Pain 2004;112(3);372-80.

49. Cowan DT, Wilson-Barnett J, Griffits P, Allan LG. A survey of chronic noncancer pain patients prescribed opioid analgesics. Pain Med 2003;4(4):340-51.

50. DuPen A, Shen D. Ersek M. Mechanisms of opioidinduced tolerance and hyperalgesia. Pain Manag Nurs 2007;8(3):113-21.

51. Galler BS, Lee D, Ma T, Nagle B, Schlagheck TG. MorphiDex (morphine sulfate/dextromethorphan hydrobromide combination) in treatment of chronic pain: three multicenters, randomized, double-blind, controlled clinical trials fail to demonstrate enhanced opioid analgesia or reduction in tolerance. Pain 2005;115(3):284-95.

52. Morita T, Takigawa $\mathrm{C}$, Onishi $\mathrm{H}$, Tajima T, Tani K, Matsubara T, Miyoshi I, Ikenaga M, Akechi T, Uchitomi Y; Japan Pain, Rehabilitation, Palliative Medicine, and Psycho-Oncology (PRPP) Study Group. Opioid rotation from morphine to fentanyl in delirious cancer patients: an open-label trial. J Pain Symptom Manage 2005;30(1):96-103.

53. Yentür EA. Opioid Kullanımında Engeller. Klinik Gelişim 2007;20(3):155-8.

54. Saffier K, Colombo C, Brown D, Mundt MP, Fleming MF. Addiction Severity Index in a chronic pain sample receiving opioid therapy. J Subst Abuse Treat 2007;33(3):303-11.

55. Richardson LP, Russo JE, Katon W, McCarty CA, DeVries A, Edlund MJ, Martin BC, Sullivan M. Mental health disorders and chronic opioid use among adolescents and young adults with chronic pain. J Adolesc Health 2012;50(6):553-8. Crossref

56. Manchikanti L, Giordano J, Boswell MV, Fellows B, Manchukonda R, Pampati V. Psychological factors as predictors of opioid abuse and illicit drug use in chronic pain patients. J Opioid Manag 2007;3(2):89-100.

57. Arnold RM, Han PK, Seltzer D. Opioid contracts in chronic nonmalignant pain management: objectives and uncertainties. Am J Med 2006;119(4):292-6.

58. Fishman SM, Wilsey B, Yang J, Reisfield GM, Bandman TB, Borsook D. Adherence monitoring and drug surveillance in chronic opioid therapy. J Pain Symptom Manage 2000;20(4):293-307.

59. Manchikanti L, Manchukonda R, Pampati V, Damron KS, Brandon DE, Cash KA, McManus CD. Does random urine drug testing reduce illicit drug use in chronic pain patients receiving opioids? Pain Physician 2006;9(2):123-9. 